\title{
"Escutar música por dentro": Sentidos da música e as aulas de técnica vocal e violão para um surdo profundo
}

Scarlat Suiti

Recebido em 24/05/2018 Aprovado em 05/09/0218 
Este texto traz um recorte de uma pesquisa realizada como requisito final para a conclusão do curso de Licenciatura em Educação Musical da Universidade Estadual de Maringá, que teve como objetivo investigar a aprendizagem musical de um aluno surdo que estuda técnica vocal e violão. A coleta de dados foi realizada por meio de observações e entrevistas semiestruturadas. Aqui, apresento inicialmente, uma breve revisão de literatura sobre a temática; na sequencia abordo a metodologia usada na pesquisa e por fim, trago parte dos resultados da pesquisa. Os dados indicam que a música na vida de um surdo não é somente de entretenimento, mas sim de um desenvolvimento social que contribui na relação dele com o seu cotidiano. Além disso, mostram parte da dinâmica e organização das aulas de violão e técnica vocal com um surdo profundo.

Palavras-chave: música e surdez, relação de um surdo com a música, surdez.

\section{INTRODUÇÃO}

Este texto apresenta parte dos resultados de uma pesquisa no campo da Educação Musical que teve como objetivo investigar a aprendizagem musical de um aluno surdo que estuda técnica vocal e violão em uma escola de música. Por meio de observações e entrevistas, a pesquisa buscou compreender o processo de aprendizagem do surdo e discutir o papel das aulas de música em sua vida. Neste artigo, abordo como é a relação do surdo com a música, bem como de que maneira são suas aulas.

O surdo é o sujeito que devido sua dificuldade ou inexistência de audição, comumente se utiliza de uma comunicação espaçovisual como principal meio de conhecer e se comunicar com o mundo em substituição à audição e em muitos casos à fala. No

\footnotetext{
${ }^{1}$ LIBRAS é a sigla de Língua Brasileira de Sinais, um conjunto de formas gestuais utilizada por deficientes auditivos para a comunicação entre eles e outras pessoas, sejam elas surdas ou ouvintes. No Brasil, a língua brasileira de sinais foi estabelecida através da Lei ${ }^{\circ}$ 10.436/2002, como a língua oficial das pessoas surdas.
} 
Brasil a língua oficial para pessoas surdas é a LIBRAS1, embora ainda haja surdos que se comunicam por gestos e/ou preferem utilizar a língua falada.

No campo da Educação Musical vários estudos abordam a música e a surdez, dentre eles destaco Ferreira (2011), Finck (2007), Oliveira (2014) e Soares (2007). Estes pesquisadores afirmam que os surdos podem sentir música de uma forma peculiar e desenvolver-se musicalmente.

Neste artigo apresento inicialmente uma breve revisão de literatura, onde apresento os trabalhos mencionados anteriormente. Na sequencia abordo a metodologia usada na pesquisa e por fim, trago parte dos resultados da investigação. Os dados indicam que a música na vida de um surdo contribui para seu empoderamento, além de o ajudar na expressão vocal. Além disso, indica que há maneiras especificas para otimizar e encaminhar as aulas de música para os surdos.

\section{O QUE AS PESQUISAS REVELAM SOBRE MÚSICA E SURDEZ?}

Ferreira (2011) analisou a música como fator de inclusão para alunos com deficiência auditiva e seu uso pedagógico no Centro de Ensino Especial 01 de Taguatinga. Os resultados de sua análise indicam que "pessoas que nasceram surdas ou adquiriram a deficiência mais tarde fazem música de qualidade e que nada difere das outras pessoas", modificando o paradigma de que somente os "ouvintes" podem adquirir habilidades musicais.

Na mesma direção, Finck (2007), ao realizar uma pesquisa para sua tese de doutorado, investigou, a partir de uma abordagem qualitativa como se dá o processo de aprendizagem musical de alunos surdos em contexto de inclusão escolar. Dentre seus objetivos estava a intenção de contribuir na sistematização de uma base para educação musical para esses alunos junto ao contexto escolar. Sua pesquisa foi desenvolvida em duas fases, a primeira envolveu observações e entrevistas com profissionais que atuam com alunos surdos, buscando o que esses profissionais pensam sobre a inserção da música na 
escola inclusiva para alunos surdos e também verificar como as unidades estavam se adaptando as políticas governamentais de inclusão. A segunda fase foi desenvolvida a partir de uma pesquisa-ação com atividades musicais práticas em uma turma de quinta série, com 35 alunos, sendo duas surdas, e, uma proposta de Oficina com sons e movimentos envolvendo 10 crianças, sendo quatro delas surdas. A análise dos dados coletados na primeira e segunda fase indica que a inserção de alunos surdos na escola e as ações inclusivas ainda não satisfazem plenamente as necessidades educacionais destas crianças. Por outro lado, a descrição das atividades práticas contribuiu para ampliar as discussões sobre aprendizagens musicais das crianças surdas e como elas se relacionam com os conteúdos musicais. A pesquisadora verificou também que, a partir da criação e da utilização e materiais adaptados e de recursos pedagógicos específicos, foi possível constatar aprendizagem musicais significativas, o que evidencia a possibilidade da estruturação de elementos de ação musical direcionada para crianças surdas em contexto inclusivo. Ela concluiu que "música e surdez não podem ser consideradas um paradoxo. Ser musical não é privilégio de seres especiais e bem dotados, mas possibilidade do homem como ser" (FINCK, 2007, p.6).

Oliveira (2014), partindo do pressuposto de que muitos consideram a música como algo inacessível para os surdos, buscou compreender as contribuições da música no desenvolvimento social do sujeito surdo. Para isso, por meio de questionário, ele analisou as respostas de 20 surdos universitários do Curso de Letras com habilitação em Libras da Universidade Federal de Goiás. Os resultados indicaram que o surdo não está alheio à música e que pode se desenvolver socialmente com o reconhecimento de vibrações sonoras e do ritmo musical.

Soares (2007), com base no material desenvolvido por Louro (2006), proporcionou diversas atividades musicais, com alunos surdos da Escola Municipal Rosa do Povo, em uma turma de alunos surdos que participa do programa do bilinguismo no estado do Rio de Janeiro, com alunos com idades entre oito e vinte anos. Estas atividades fizeram parte de uma proposta educativo-musical que envolveu a apreciação e a execução 
musical. A autora organizou os dados a partir de observações das reações dos alunos concluindo que uma das maneiras do surdo ouvir e sentir a música é por meio da vibração. Em suas palavras "a vibração é um parâmetro muito importante para o aluno surdo, pois através dela consegue diferenciar timbre, que para nós são diferenciados através da audição" (SOARES, 2007, p. 22).

Entender a vibração como uma maneira importante de ouvir e sentir música é também afirmada por Evelin Glennie (2003), uma musicista surda-cega que toca bateria. De acordo com ela

Depois que Elaine começou a participar das aulas, isso fez diferença. Acho que os bebês se sentem mais seguros com a presença dela, mas acredito que se ela precisar sair da sala, a aula continuará tranquilamente, porque os bebês têm, agora, mais confiança em nós, uma vez que estamos com eles há um bom tempo e já nos familiarizamos (Diário de Campo, 2015, Aula 12, Infantil I).

\section{COMO REALIZEI A PESQUISA?}

Com o intuito de melhor compreender o processo de aprendizagem de um aluno surdo, bem como discutir sobre como a música se faz presente em sua vida, desenvolvi um estudo de caso (Yin, 2005), a partir de observações e entrevistas semi-estruturada, com um aluno surdo e seus professores de música. Para isso busquei localizar em Maringá uma experiência de aulas de música com surdo, localizando a professora de canto Francyene, que ministrava aulas de canto para um surdo em uma escola especializada em música. Entrei em contato com ela, que foi extremamente solícita e abriu sua aula para pesquisa. A partir deste contato e dos objetivos da pesquisa, organizei um roteiro prévio de observação e de entrevista semi-estruturada para a professora e o aluno.

Agendei uma observação da aula de técnica vocal com o intuito de conhecer o aluno de Francyene e já começar a compreender como ocorria a aprendizagem musical do aluno surdo. Nesta aula conheci Sérgio, na ocasião com 61 anos, surdo profundo, que faz uso de um aparelho auditivo retro 
auricular, que ajuda o ouvido a perceber os sons, amplificálos e transmiti-los através do ouvido. Sérgio é estudante de LIBRAS há um ano, há cinco anos faz acompanhamento fonoaudiólogo, e há três anos faz aulas de técnica vocal2. Ele dirige, mora sozinho, tem namorada, é pai de um filho já adulto e é gerente administrativo da empresa da família.

Sua professora Francyene, na ocasião com 34 anos, é Bacharel em Regência Coral, Bacharel e em Canto Lírico pela Universidade Estadual de Maringá - UEM, e é também dentista.

Em contato com Sérgio soube que ele também estuda violão. Imediatamente consegui o telefone do professor e já fiz um agendamento. O professor de violão chama-se Edson, na ocasião da entrevista estava com 48 anos, Licenciado em Música pela Universidade Estadual de Londrina- UEL e com pós-graduação em arranjo pela mesma universidade. Atua como professor de violão e guitarra e sua primeira experiência em dar aulas para um surdo foi com Sérgio.

Ao longo da coleta de dados, realizei quatro observações das aulas de técnica vocal, que foram gravadas e registradas em cadernos de campo, e seis entrevistas, sendo: uma entrevista com a professora de canto Francyene, três com Sérgio, e, duas com o professor de violão Edson. O local e o horário das entrevistas foram escolhidos pelos entrevistados de acordo com suas disponibilidades, algumas ocorreram em seus locais de trabalho e outras em suas casas. Todas as entrevistas foram gravadas e transcritas.

Neste processo, o desafio foi a comunicação com Sérgio, que foi educado com o método do oralismo ${ }^{3}$, mas, por vezes era difícil entendê-lo com clareza. Poucas vezes ele fazia uso da linguagem de sinais, e as vezes ele respondia algo diferente do que eu havia perguntado. Isso me levava a repetir as perguntas de forma diferente para conseguir obter as respostas correspondentes.

\footnotetext{
${ }^{2}$ Mais tarde, em entrevista com Sérgio, soube que ele também fazia aulas de violão há quatro anos, conforme abordo mais abaixo no texto.

${ }^{3}$ Surgiu por volta do século XVIII e a partir das resoluções do Congresso de Milão (1880). $\mathrm{Na}$ época a língua de sinais foi oficialmente proibida nas escolas e a comunidade surda foi excluída da política e instituições de ensino. Essa proposta pretendia que os surdos fossem reabilitados, ou "normalizados", pois, a surdez era considerada uma patologia, uma anormalidade. Eles deveriam comportar-se como se ouvissem, ou seja, deveriam aprender a falar.
} 


\section{COMO E POR QUE SÉRGIO SE INTERESSOU EM ESTUDAR MÚSICA?}

Para compreender como a música está presente na vida de Sérgio, coloquei como pergunta inicial da entrevista como se deu o interesse por esta área de conhecimento e os porquês de ele resolver estudar técnica vocal e violão. A resposta de Sérgio foi inusitada. Segundo ele a decisão ocorreu devido ao fato de ter recebido "uma mensagem espiritual". Ele relata que: "um espírito falou música para mim" (fez sinal de que ouvia a música).

A ideia de que foi um espírito quem o conduziu para música é a explicação que ele encontrou, considerando que ele não ouve música de forma convencional. Ele se remete a algo metafisico, afirmando espontaneamente, com gestos como ele recebeu a mensagem do espírito. Isso sugere que há uma busca de entendimento pela surdez e a forma como os surdos desenvolvem sua sensibilidade para manifestações diversas. Sérgio se remete a algo impalpável, para dar sentido ao motivo pelo qual decidiu fazer música. Parece que o que comumente é chamado de inspiração ou mesmo desejo, para ele tem o nome de "espírito".

Sobre a escolha de estudar especificamente técnica vocal e violão, Sérgio explica que viu o grupo The Beatles ${ }^{4} \mathrm{e}$ se encantou: "Eu vi os Beatles, nossa que legal eu queria fazer igual!". Além disso, ele ouve música no computador e aprecia muito: "escuta música5 em computador, é maravilhoso... rádio, e queria fazer igual."

Nesta parte, não pude continuar a conversa sem antes tentar entender como Sérgio escutava música. E ao perguntar a respeito ele me respondeu de uma forma autêntica: "eu escuto música por dentro". Obviamente que o aparelho auditivo que ele usa permite a experiência de uma escuta diferente da convencional aprendendo a identificar os sons, afirmando que gosta de senti-los. Contudo, 0 "escutar música por dentro" está relacionado a uma experiência

\footnotetext{
${ }^{4}$ The Beatles foi uma banda britânica, de rock, formada em Liverpool, cidade do noroeste da Inglaterra, que ficou famosa em todo o mundo e influenciou toda uma geração, movimento que a imprensa britânica chamou de Beatlemania. Fonte: https:// www.ebiografia.com/the_beatles/.

${ }^{5}$ A sintaxe da frase é a original de Sérgio. Ele não usa as regras convencionais da língua portuguesa para se comunicar. Mantive suas falas no formato original.
} 
mais profunda, onde a vibração sonora e os sentidos que ele atribui ao que está ouvindo, permitem uma experiência musical que o ouvinte pode não conseguir experienciar. Assim, certamente, ele ouve The Beatles de forma peculiar e muito subjetiva.

Ao longo das entrevistas eu repeti as mesmas perguntas na intenção de melhor entender suas respostas. Isso porque nem sempre compreendia o que ele falava. Em um outro momento, ele contou que na infância estudou em um colégio para surdos em São Paulo e lá teve aula de música. A professora o incentivou a tocar bateria, porém ele não o fez naquela época, por falta de tempo.

Contudo, assim que teve oportunidade ele começou a estudar música. Em suas palavras: "Eu gosto de violão. Canto. Feliz. Se não sabe tocar violão fica triste. Antes minha vida não pensa, agora mudou, agora eu penso, penso em música. Eu estudo. Deixa, agora mais feliz" (Sérgio).

Neste depoimento é nítido que a música ocupa um papel importante para o estado de humor de Sérgio. Ele atribui parte de sua felicidade ao fato de tocar violão e cantar. Isso indica que há uma realização pessoal nesta atividade que não é alcançada por outras que ele realiza. Mais tarde, em outro trecho da entrevista, entendo que isso ocorre porque ele sente valorizado e sabe que as pessoas que ouvem ele tocar e cantar se surpreendem: "todo mundo, não vê surdo cantando, tocando violão, ai não acredita".

Parece que o fato de as pessoas que o ouvem ficarem surpreendidas, dá a ele uma sensação de empoderamento, que o deixa feliz. A surpresa que "as pessoas" demostram deve estar relacionada ao próprio estigma de que música é uma manifestação presente no mundo dos ouvintes e que não faz parte das atividades de um surdo. Isso, contudo parece ser um dos aspectos que contribuiu para que Sérgio se envolva ainda mais com música, se dedicando e sentindo-se feliz com isso.

Assim, a repercussão na vida do surdo de tocar um instrumento e cantar vai além de fazer música. Na entrevista com a professora de técnica vocal de Sérgio, Francyene, duas situações indicaram o quanto que o fato de tocar e cantar contribuíram para o desenvolvimento da autonomia do aluno. A professora compartilhou que, embora ele já tivesse mais de 60 anos, havia uma co-dependência com o filho. Sempre que havia a necessidade de definir alguma questão relacionada a parte 
funcional das aulas, era o filho quem vinha tratar e decidir sobre o assunto. Porém, ao longo das aulas, Sérgio foi se sentindo mais confiante e consciente de que podia tomar suas próprias decisões. Percebendo a importância desta autonomia, a professora pediu ao filho que permitisse que tudo o que fosse relativo as aulas de canto fossem tratado e definido diretamente com Sérgio. Ela argumentou que o próprio aluno era quem pagava por suas aulas e que ele tinha condições de compreender e se comunicar sobre todos os assuntos pertinentes as aulas. Esta situação ofereceu a Sérgio uma mobilidade e um senso de poder que deu a ele a liberdade de escolhas e decisões. Se ele podia escolher estudar música, bem como pagar por suas aulas, ele podia também decidir e opinar sobre os demais aspectos aí envolvidos (horários, reposição, preços, etc).

Esta atitude repercutiu em outros setores da vida dele. Ele contou a Francyene que dias depois de decidir a ser responsável por suas escolhas, recebeu um bilhete da professora de LIBRAS solicitando que o filho entrasse em contato com ela para discutir sobre os horários das aulas. Mas, afirmou que foi categórico, afirmando: "não professora, você pode combinar diretamente comigo" (relato de Francyene sobre Sérgio). E de acordo com Francyene, após relatar sua experiência, ele afirmou feliz: "aprendi com você".

Este depoimento vai ao encontro do que Edson, o professor de violão, contou em sua entrevista:

O legal é que pra ele [Sérgio] isso está sendo bom. O filho dele falou que ele se retraía muito. Por causa da surdez, se retraia muito. $E$ isso está fazendo com que ele, perca essa timidez de falar e ajuda ele se comunicar. O bom é isso não fica restrito ao âmbito musical, isso aí é pra vida, onde ele se relaciona... com as pessoas que ele se relaciona. (Edson)

Este papel socializador da música na vida do surdo também é encontrado no depoimento de Bonvenuto que é professor de música para surdos. Ele afirma que para os surdos a música e uma "porta para outras coisas (...) para eles é uma questão social". Isso porque oportuniza outras experiências que contribui na auto-estima e empoderamento para o ser e o estar social. 


\section{MAS... COMO SÃO AS AULAS DE MÚSICA COM SÉRGIO?}

Além de entender o significado da música na vida de Sérgio, havia também o interesse em conhecer como se davam as aulas de música com ele. A partir das observações, bem como das entrevistas com os professores, pude ver a estrutura das aulas e os encaminhamentos pedagógicos-musicais. Ambas as aulas, técnica vocal e violão, eram semanais, com duração de 1 hora, e na mesma escola de música.

Ambos os professores relataram que nunca antes tinham tido alunos surdos. Isso fez com que encarassem esta oportunidade como um desafio para sua própria prática docente. Professor Edson relatou que, embora não tivesse nenhuma experiência com Surdez, decidiu abordar as aulas como faz com todos seus alunos: conhecer o aluno e ir encaminhando as aulas a partir de como ele funciona. Contudo, afirmou que tinha muitas dúvidas sobre surdez e os meios metodológicos a se usar com Sérgio "é assim como qualquer aluno que você vai começar a dar aula, você vai conhecendo com o tempo né, você vai testando como ele funciona, você vai buscando, busca, ele usa o aparelho ai pensava: o que será que ele escuta?" (Edson).

A professora de canto Francyene, relatou que ao iniciar as aulas, agendou uma conversa com a fonoaudióloga que atendia Sérgio. Isso porque sentiu a necessidade de saber mais sobre a surdez e o desenvolvimento da fala do aluno. Na conversa, descobriu o quanto Sérgio tinha uma facilidade de perceber ritmos, passando esta informação para o professor de violão. Ambos entenderam que desenvolver atividades relacionadas a este aspecto poderia ser um caminho a ser seguido.

$\mathrm{Na}$ conversa, soube também da dificuldade de Sérgio diferenciar algumas escutas e pronuncias, como do F e V, por exemplo, FACA x VACA. Esta informação trouxe a professora um desafio: desenvolver exercícios músico-vocais que pudessem contribuir para sanar esta dificuldade. Sendo o aluno muito visual, a professora mantinha-se bem à frente do aluno articulando as palavras e o aluno tocava em sua região do 
pescoço para sentir a vibração/movimento, usando de auxilio a escrita e desenho no caderno.

Nas aulas que observei, verifiquei que Sérgio iniciou as aulas da mesma maneira que é comum em um processo pedagógico que envolve a voz/canto: preparando o corpo para tal tarefa. A professora lançou mão de elementos da yoga para alongamento corporal e exercícios de respiração. Para isso fez uso de um tapete emborrachado, onde o aluno, descalço, conseguia sentir melhor as sensações provocadas pelos movimentos e mais tarde a vibração dos exercícios vocais acompanhados pela professora ao piano.

Os chamados vocalizes ${ }^{6}$, foram realizados com a professora olhando diretamente para Sérgio, explicando como deveria repeti-los e gesticulando e articulando exageradamente para que o aluno fizesse uso da leitura labial, que aliado ao que conseguia ouvir com o aparelho, pudesse reproduzir. Em vários exercícios vocais acompanhados do piano, Sérgio colocava a mão sobre o instrumento buscando sentir a vibração, que aliada a voz, as referências de altura que a professora indicava com uma das mãos, e com a escrita, faziam com ele conseguisse emitir um som próximo a altura desejada e tocada no piano. Ou seja, emitir um vocalize próximo ao que se considera afinado, no entendimento tradicional de música. E por fim se trabalhava o repertório, no qual professora e aluno utilizavam também de celular para acompanhar letra e cifra, mantendo a postura de um frente ao outro.

O recurso da escrita era usado em todas as aulas. Segundo a professora, o acompanhamento da letra das músicas, com anotações e dicas de emissão vocal o ajudavam a entender a prosódia e fonética. Ou seja, Francyene não apenas escreve as palavras, mas também a pronuncia e até mesmo a direção das alturas.

\footnotetext{
${ }^{6}$ Os vocalizes são exercícios vocais feitos com diferentes intervalos musicais dispostos melodicamente (uma nota após a outra) e acompanhados por instrumento harmônico (piano ou violão), assegurando a afinação do cantor. Os vocalizes devem ser feitos sempre com o uso correto da respiração, articulação e ressonância, são criados com vogais (vocálicos), silabas (silábicos), palavras e frases. Os intervalos musicais na vocalização ajudam a educar o ouvido e trabalham nossas pregas vocais. Tutti Bâe http://www.voxmusicstudio.com.br/saiba-o-que-sao-vocalizes/.
} 
O uso da escrita é recorrente nas aulas de técnica vocal e também nas de violão. Professor Edson desenha flechas correspondentes ao ritmo para facilitar que o aluno cante enquanto estiver tocando o violão.

"A esse sistema de elaborar as flechas é diferente, tem gente que não precisa, mas como ele é muita visual, foi uma maneira de ajudar ele. E deu certo, então eu continuei (...) tem as flechas com as sílabas em cima das palavras que ele fala, a melodia junto com o ritmo" (EDSON)

As aulas de violão sempre se iniciam com a afinação do violão, seguindo para revisão do que foi trabalhado na aula anterior, com atenção ao ritmo, dedilhado e/ou troca do acorde, dependendo da música estudada.

Ao longo das aulas, Edson explica que dá ênfase no ritmo. Ele conta o processo:

Eu pego o violão por exemplo, aí eu bato - geralmente eu uso o corpo dele, bato no ombro, em algum lugar do corpo dele - como é o ritmo. Aí escrevo o movimento da mão, pra baixo pra cima, e aí as vezes ele fica só fazendo o movimento. Depois coloco no violão e assim vai. E ele aprendeu bastante ritmo. (EDSON)

Sérgio tem um repertório pessoal de músicas que gosta de ouvir e cantar. Contudo, nas aulas de música nem sempre o repertório preferido é o abordado. Segundo ele, suas preferencias são por músicas gospel, de rock e de samba, além de músicas românticas. Porém, por acreditar que ainda tem muito a aprender, opta por seguir o repertório indicado pelos professores.

Este modelo de definição de repertório nas aulas de música ainda é recorrente, embora muitas pesquisas já mostram que ao fazer uso do repertório do aluno as aulas de música fluem de maneira mais eficiente. No caso de Sérgio, e em tantas outras situações de ensino de música, falta, talvez, um diálogo maior entre professor e aluno.

No processo das aulas de Sérgio, contudo, percebe-se a preocupação dos professores em fazê-lo ver e sentir a música para então executá-la. O uso da escrita, o toque, a percepção da música por meio do corpo e a ênfase no visual, são aspectos 
que otimizam as aulas e contribuem para o processo de aprendizagem musical do aluno.

O que Finck (2009) em sua tese aborda que entre as estratégias a serem utilizadas para ensinar música ao aluno surdo, a primeira estratégia adaptativa é o apoio visual e tátil. Aspectos visuais incorporados juntamente com os elementos sonoros e táteis mostrou-se eficaz em suas adaptações pedagógicas para a realização de atividades musicais.

\section{CONSIDERAÇÕES FINAIS}

Neste texto apresentei parte dos dados de uma pesquisa que abordou a música na vida de um surdo. Aqui, busquei apresentar dados relativos aos sentidos da música para o surdo, bem como aspectos de aula de música com surdos. Para isso desenvolvi observações e entrevistas semiestruturada com Sérgio um aluno surdo, e seus professores de música.

Embora tenha me sentido desafiada em compreender a fala de Sérgio nas entrevistas, os dados da pesquisa, contribuíram para maior compreensão de como o surdo ouve e se relacionada com música. A dificuldade na comunicação do aluno parece não ser uma barreira para seu aprendizado musical. Isso porque os professores fazem uso de recursos que favorecem a relação dele com a música e com os conteúdos abordados (como ritmo, emissão vocal, dicção). Por exemplo, o uso da escrita e de sentir no corpo o ritmo e as vibrações sonoras, favorecem a aprendizagem.

Se faz de fundamental para a proficuidade de todo o processo de aprendizagem musical de Sérgio, a postura dos professores em relação ao aluno. Estes acreditaram nas possibilidades do aluno, buscando formas de atuar, empenhando-se em desenvolver uma aprendizagem significativa. Este exemplo, contudo, não justifica a necessidade de uma formação de professores de educação musical específica para a atuação nesta área.

O empoderamento que a música parece oferecer a Sérgio o prazer que ele sente em tocar e cantar, indicam que o papel da música em sua vida não somente de entretenimento, mas sim de um desenvolvimento social que contribui na relação dele com o seu cotidiano. Sérgio não fixou seu foco na falta da audição, mas 
sim em suas possibilidades, no enfrentamento e na transformação de sua realidade. A música para ele é uma possibilidade.

A forma específica como Sérgio ouve música e se relaciona com ela, vai ao encontro do que a literatura menciona: a surdez não é uma barreira para experiências musicais. Cabe ao campo da Educação Musical investir em pesquisas e em estratégias pedagógicas que possibilitem mais e melhores interações, compreensões e encaminhamentos pedagógicos profícuos para as aulas de música para surdos. 


\section{REFERÊNCIAS}

FERREIRA, Paulo R. P. A música como fator de inclusão para alunos com deficiência auditiva. 2011. 65 p. Monografia de Especialização. Universidade de Brasilia, Brasilia, 2011.

FINCK, Regina. Surdez e Música: será este um paradoxo? XVI Encontro Anual da ABEM e Congresso Regional da ISME na América Latina. Anais. Santa Catarina, 2007.

FINCK, Regina. Ensinando Música ao Aluno Surdo: perspectiva para a ação pedagógica inclusiva. 2009. Tese (Doutorado em Educação) Programa de Pós-Graduação em Educação, Faculdade de Educação. Universidade Federal do Rio Grande do Sul, Porto Alegre, RS.

GLENNIE, Evelyn. Palestra para TED-Ideas Worth Spreading, 2003. Disponível em: https://www.youtube.com/watch?v=IU3V6zNER4g. Acesso em 11 de jun. de 2016.

KUNTZE, Vivian Leichsering. A relação do surdo com a música: Representações sociais. 2014. Dissertação (Obtenção do grau mestre em Música) Centro de Artes da Universidade Estadual de Santa Catarina - Florianópolis.

OLIVEIRA, Hilkia Cibelle da Cruz. O desenvolvimento do sujeito surdo a partir da música. Centro virtual de cultura surda, Revista virtual da cultura surda. Editora Arara azul. Edição No14/ setembro de 2014.

SOARES, Cristina da Silva. Educação Musical para surdos: uma experiência na escola municipal Rosa do Povo. Trabalho de Conclusão de Curso. P. 38. Rio de Janeiro: Universidade Federal do Estado do Rio de Janeiro, 2007. Disponível em: https://musicaeinclusao.wordpress. com/2013/06/09/da-silva-cristina-soares-educacao-musical-parasurdos-uma-experiencia-na-escola-municipal-rosa-do-povo-2008/ Acesso em 02 de maio de 2018.

YIN, Robert K. Estudo de caso - planejamento e métodos. (2Ed.). Porto Alegre: Bookman. 2001. 